\title{
Compact Storage Equipment: Where to Use it and Where Not
}

Dr. Muller, formerly director of libraries, Southern Illinois University, is now assistant director of libraries, University of Michigan.

$\mathrm{T}$ HE IDEA that you can pack twice as books into a given floor area as is possible under conventional stack shelving appeals to librarians. Many librarians, faced with the necessity of having to provide more and more shelving space for increasing numbers of acquisitions, have been attracted by the announcement of several manufacturers that it is now possible to double or, in some cases, more than double the stack capacity of a library.

Although possibilities for compact storage have been explored since the days of Melvil Dewey and experimentation can be traced to the early nineties of the nineteenth century, ${ }^{1}$ it has only been since 1950 that compact storage equipment has been widely exhibited, advertised, and installed. Four manufacturers are currently competing with each other in this field, ${ }^{2}$ and two others are likely to enter the arena before very long. ${ }^{3}$

Faced with competing and conflicting claims, librarians as potential customers may tend to become bewildered. Should they consider this type of equipment at all? Will it increase or decrease service costs?

\footnotetext{
1 Rider, Fremont. Compact Book Storage. New York. Hadham Press, I 949 , p. 30.

2 W. R. Ames Company, San Francisco, Calif.; Art Metal Manufacturing Company, Jamestown, N.Y.; Hamilton Manufacturing Company, Two Rivers, Wis.; Remington Rand, Inc., New York.

3 Globe-Wernicke Company, Cincinnati, Ohio; Virginia Metal Products Company, Orange, Va.
}

How will library patrons react to the equipment? Will we really save any money in the long run? If we decide to go into compact storage equipment, which type should we select? Will the equipment stand up under wear? Should we not rather wait until others have made mistakes? In studying compact storage installations, what aspects should we focus attention on? What about storage warehouses and cooperative storage warehouses in relation to compact storage equipment?

In this brief report, we shall not try to answer all these questions. We shall assume that you have looked at and pondered over the equipment offered by different manufacturers and have decided to give them serious consideration. Instead of trying to tell you which of the four systems of compact storage is best, we shall merely give brief descriptions of the equipment, indicate the degree of compactness they can achieve under identical conditions, and suggest where such compact book storage equipment might be used to advantage and where it should not be used.

The calculations of the degree of compactness, expressed in terms of increase in storage capacity, are based upon layout drawings of equipment in areas obstructed only by uniformly placed columns 23 feet on centers, with stack ranges in a freestanding arrangement. We assumed that no shelf section would have more than 7 levels of shelves or drawers.

(I) The compact storage system advocated by Remington Rand employs four- 
way stack columns to make it possible to turn the direction of stack ranges by 90 degrees; it achieves compactness through aisle reduction from a width of about 36 inches to 20 inche's and elimination of a center aisle. If no center aisles or cross aisles are provided both before and after the change, storage capacity can be increased by about $40 \%$. The claim made in advertisements that storage capacity can be increased by $69 \%$ is true only if you assume a relatively comfortable provision of aisles before the change and no cross aisles after the change.

(2) The Ames Stor-Mor Book units consist of double-headed drawers, approximately 6 feet in length, having a drawerhead at each end. The drawers are designed to bridge alternate aisles in a stack area making use of the existing stack columns, but the drawers can also be used in a free-standing arrangement. The length of the drawer runs perpendicular to the length of conventional shelving. The shelves are adjustable by means of bolts. The width of the drawer is approximately 18 inches, occupying one-half of the space of the conventional book shelf; two drawers are placed side by side to occupy the 3 foot section provided for book shelves. This type of drawer makes use of the conventional pattern of stack columns for its support and does not require additional supports. The additional dead loads imposed by the weight of the drawer unit and the increased number of books which they carry are transmitted to the existing stack columns. Multi-tier construction can, therefore, be converted from conventional shelving to compact storage drawers without providing additional structural framing to the extent that the existing stack columns are capable of carrying the increased loads. The drawer accommodates two rows of books for its entire length. Contents are identified by $3^{\prime \prime} \times 5^{\prime \prime}$ cards, two card holders being provided on each drawer head. In a free-standing arrangement where no cross aisles are provided, storage capacity can be increased by $76.2 \%$, assuming range aisles of 43 inches in width and the use of book supports to separate the two halves of each double-headed drawer. If no book supports are used and if conventional wall shelving is used in conjunction with the Ames units, storage capacity can be increased to $90.1 \%$ as compared to conventional shelving alone.

(3) Hamilton Compo units consist of single-headed drawers, available in lengths varying from about 3 to 4 feet and in widths varying from 18 to 26 inches, supported by four-way stack uprights, making conversion from conventional to compact storage easily possible. All sliding shelves are individually adjustable vertically on Iinch centers without the use of bolts, nuts, or loose parts. In a free-standing arrangement where no cross aisles are provided, storage capacity can be increased by I09.3\%, assuming range aisles of 46 inches in width.

(4) Art Metal swing units consist of two hinged shelf sections placed in front of each regular adjustable shelf section; each swing unit occupies a little less than one-half of the length of a regular shelf section, permitting the swing units to open out into the range aisle, thus exposing to view the shelves that are hidden when the swing units are closed. It is possible to place either 4 or 8 swing units (a single or a double row of shelf sections) on both sides of a regular shelf section. In a freestanding arrangement with 4 swing units, capacity can be increased by $52.9 \%$, assuming range aisles of 28.5 inches in width. With 8 swing units, capacity can be increased by $73.4 \%$, assuming range aisles of 38 inches in width.

Table I is included to show how the above percentages were obtained.

Before enumerating the uses of the compact storage equipment just described, we must attempt to clarify the one question that is of crucial significance, namely: Will the installation of compact storage equipment enable librarians to bring about any overall economy in book storage costs? Before compact storage became widely available, Fremont Rider stated that "the only place where savings would be affected would be in the amount (per book stored) of the stack building shell which would 
TABLE I

Capacity Increases for Different Compact Storage Plans With Free-

Standing Stacks for an Area Measuring 23 Feet by 23 Feet

\begin{tabular}{|c|c|c|c|c|c|c|c|}
\hline & $\begin{array}{l}\text { Range } \\
\text { Aisles } \\
\text { (inches) }\end{array}$ & $\begin{array}{c}\text { No. of } \\
\text { units } \\
\text { per bay } \\
\text { (Maximum) }\end{array}$ & $\begin{array}{l}\text { No. of } \\
\text { Lineal } \\
\text { ft. per } \\
\text { unit }\end{array}$ & $\begin{array}{l}\text { No. of } \\
\text { vol. per } \\
\text { unit }\end{array}$ & $\begin{array}{l}\text { No. of } \\
\text { vol. per } \\
\text { bay }\end{array}$ & $\begin{array}{l}\text { Gain } \\
\text { over } \\
\text { conven- } \\
\text { tional } \\
\text { shelving }\end{array}$ & $\begin{array}{l}\text { Percent- } \\
\text { age } \\
\text { gain }\end{array}$ \\
\hline $\begin{array}{l}\text { Conventional shelving } \\
8^{\prime \prime} \text { shelves }\end{array}$ & 38.7 & 35 & $4 \mathrm{I} . \mathrm{I}$ & 247 & 8,645 & - & - \\
\hline $\begin{array}{l}\text { Aisle Reduction Plan, } \\
\text { Moderate, } 8^{\prime \prime} \text { shelves }\end{array}$ & 29.5 & 42 & $4 \mathrm{I} \cdot \mathrm{I}$ & 247 & 10, 374 & $\mathrm{I}, 729$ & 20.0 \\
\hline $\begin{array}{l}\text { Aisle Reduction Plan, } \\
\text { Severe, } 8^{\prime \prime} \text { shelves }\end{array}$ & 22.9 & 49 & $4 \mathrm{I} \cdot \mathrm{I}$ & 247 & I 2,103 & $3,45^{8}$ & 40.0 \\
\hline $\begin{array}{l}\text { Art Metal, } 4 \text { swing units, } \\
8^{\prime \prime} \text { shelves (Fig. I) }\end{array}$ & 28.5 & 28 & 78.4 & 472 & I 3,2 I 6 & $4,57^{I}$ & 52.9 \\
\hline $\begin{array}{l}\text { Art Metal, } 8 \text { swing units, } \\
8^{\prime \prime} \text { shelves (Fig. } 2 \text { ) }\end{array}$ & 38.0 & $2 I$ & I I 9.0 & 714 & I 4,994 & 6,349 & $73 \cdot 4$ \\
\hline $\begin{array}{l}\text { Ames, double range drawers } \\
\text { with book supports } \\
\text { (Fig. 3) }\end{array}$ & 43.0 & 17 & I 55.5 & 896 & I 5,232 & 6,587 & 76.2 \\
\hline $\begin{array}{l}\text { Ames, double range drawers } \\
\text { without book supports } \\
\text { plus conventional shelves } \\
\text { at end walls }\end{array}$ & 43.0 & $\begin{array}{c}\text { I } 7 \text { plus } \\
4 \cdot 7 \text { single- } \\
\text { faced bracket } \\
\text { sections }\end{array}$ & $\begin{array}{c}\text { I } 55.5 \\
\text { (Ames) } \\
20.5 \\
\text { (bracket) }\end{array}$ & $\begin{array}{c}933 \\
\text { (Ames) } \\
\text { I } 23 \cdot 5 \\
\text { (bracket) }\end{array}$ & I 6,437 & $7,79^{2}$ & $90 . \mathrm{I}$ \\
\hline $\begin{array}{l}\text { Hamilton drawers i } 8^{\prime \prime} \text { wide, } \\
3^{\prime} \text {-IO" deep, } 7 \text { rows of } \\
\text { shelves (Fig. 4) }\end{array}$ & $4^{6.0}$ & 58 & $52 . \mathrm{I}$ & 312 & I 8,096 & $9,45^{\mathrm{I}}$ & 109.3 \\
\hline
\end{tabular}

* Figures follow article.

be required; and though this saving might be material, the extra cost of the stack installation in it would probably more than offset the saving. What we have here again, in other words, is a greater compactness, but no overall economy." 4 If this statement of Fremont Rider's is true, then there may be no real advantage in using compact storage. To answer the question as to whether overall savings can be achieved through compact storage equipment, we must keep in mind that there are basically two factors involved: (I) The cost of the compact storage equipment and (2) the cost of the building floor area that has been saved through the use of compact storage equipment. If the construction cost of the saved floor area is about the same as the purchase price of the compact storage equipment, then there may be no great advantage in going into compact storage equipment.

Let us assume that we need to shelve

${ }^{4}$ Rider, op. cit., p. 34.
I00,000 volumes at 6 volumes per lineal foot with conventional bracket-type shelving and with stack aisles that are about $3 \mathrm{ft}$. wide but no cross aisles. To shelve Ioo,ooo volumes will require 6, I I9 sq. $\mathrm{ft}$. At a building cost of about $\$ \mathrm{I}_{5}$ a sq. ft., which is about what non-air-conditioned buildings without equipment would cost in I 954, 6, I I 9 sq. ft. will cost \$91,785. To this figure should be added the cost of conventional bracket-type shelving for IOO,OOC volumes, which is estimated to be about \$ 5,300 , yielding a total of \$107,085.

Let us now see what we can gain with compact storage equipment, and let us select the Hamilton Compo stacks for purposes of demonstration. When we use Hamilton Compo stacks, instead of requiring a floor area of 6,1 I9 sq. ft., we shall need only 2,923 sq. ft. Hence the cost of the floor area will be only $\$ 43,845$ (as against $\$ 91,785$ under conventional shelving). To this figure, we must now add the cost of the Hamilton Compo units for I00,000 
volumes, which will amount to approximately $\$ 53,667$, yielding a total of $\$ 97,5$ I 2 .

The combined cost of shelving plus building construction, as we have just shown, will be $\$ 107,085$ for conventional brackettype shelving, but only $\$ 97,5$ I 2 with the use of Hamilton Compo stacks. The saving achieved through the use. of compact storage equipment is thus $\$ 9,573$, or not quite $9 \%$ of the cost of conventional shelving. This saving of $9 \%$ looks a great deal less impressive than the claims made in advertisements that you can double or more than double storage capacity. It is true that you can double your storage capacity, but it is equally true that you cannot cut your total book storage cost in half through compact storage equipment at present price levels. In a building costing about $\$$ I5 a sq. ft., the most we can expect is an overall economy of $9 \%$, assuming a tightly packed arrangement with no cross aisles or stack stairs and with stack sections free-standing. In multiple-tier stacks, the savings achievable through compact storage equipment may be close to $20 \%$; and in unusually expensive air-conditioned buildings, the overall savings might run as high as 25 to $30 \% .^{5}$ In most cases, $25 \%$ is probably the maximum overall economy that can be achieved through the use of currently available compact storage equipment at present price levels (See Figure 5).

Fremont Rider's prediction that no overall economy is likely to be achieved through the use of compact storage equipment, therefore, requires some modification in the light of our cost analysis. We must admit that some overall economy can now be achieved, but that the savings will not be over $25 \%$ in most cases and that they will usually be

\footnotetext{
5 For a more detailed analysis of the relationship be tween the relative expensiveness of a library building and the combined cost of building construction plus shelving, see the author's "Evaluation of Compact Book Storage Systems," in the Proceedings of the 3rd ACRL Library Building Plans Institute, Madison, Wisconsin, in ACRL MONOGRAPHS. No. I I, published by the AssoSpring, I 954 .
}

JULY, 1954 less. Furthermore, we should add to the savings achievable in the combined cost of floor area construction and shelving, certain additional savings that are more difficult to express in precise terms of dollars and cents.

Compact storage will produce savings in ( I) lighting installation and maintenance, (2) the installation of floor covering and floor maintenance, (3) the cost of hauling books to the delivery desk and returning them, (4) the installation and maintenance of heating and ventilating equipment, and (5) janitorial maintenance. These savings in cost must be balanced against disadvantages allegedly associated with compact storage equipment: (I) Books are less directly accessible. (2) Movable parts may require maintenance. (3) Moving of drawers or hinged doors may cause noise. (4) Shelving, shifting, and collecting of books may require more time and motion and may, therefore, involve greater labor costs. (5) Drawers and hinged doors may block aisles and become hazards, causing accidents. (6) Time may have to be expended in teaching library users who are not mechanically inclined how to operate drawers or hinged doors with safety. (7) Compact storage units are perhaps not too practical in open stacks despite claims to the contrary.

Librarians who feel that the disadvantages of compact storage equipment outweigh the advantages are not likely to resort to compact storage unless forced to do so by conditions over which they have no control. Let us briefly enumerate and discuss some of the conditions under which compact storage equipment might be used in preference to conventional bracket-type shelving:

(I) If a library is located where the land value is very high and where vertical building expansion is impossible, the cost of construction of a horizontal library extension might be so high that it would be considered out of the question. In cases of this sort 
and also in cases where land is simply not available at whatever cost, the use of compact storage equipment may be the only solution to the problem of providing more shelf space.

(2) If the storage capacity of a given room in a library must be expanded, but there is no opportunity for enlarging the room and weeding is out of the question, compact storage equipment may be the answer. Compact storage equipment may be suitable as wall shelving in such situations as well as for a solid block of stacks, provided that the floor strength is sufficient for the added load.

(3) In situations where funds for a substantial building expansion are not likely to be available for some time to come, yet the stacks are completely filled, it may be possible to achieve some temporary relief, possibly on an annual basis, by means of installing compact storage equipment a few sections at a time. Through such gradual expansion of the shelving space, it may be possible to provide all the space that is needed periodically until funds for a building expansion become available.

(4) In libraries with free-standing stacks, it is always possible to reduce the width of aisles between ranges to a minimum of 20 to 22 inches. Such aisle reduction with conventional shelving is also possible where fixed supporting columns are used if they are coverted into four-way columns as advocated by Remington Rand, * Incorporated. Aisle reduction will increase storage capacity by a maximum of $40 \%$ and at a relatively low cost; it is probably the least expensive type of compact storage.

(5) If a library building is extremely expensive, say with average square foot costs of between $\$ 25$ and $\$ 50$, the relative savings obtained through compact storage equipment (as against building expansion) might be sizable. For such buildings, compact storage equipment might be suitable.

(6) In situations where the appearance of the library building is an important factor and where either vertical or horizontal expansion would spoil the architectural style, book storage capacity might best be increased through the use of compact storage equipment.

We may now ask ourselves where com- pact storage equipment should not be used: ( I) Many librarians would probably object to the use of compact storage equipment for open stacks, except for little-used collections. However, compact storage has been used for open stacks. (2) When the library building in question is a very cheap building, say one that costs \$IO or less per square foot, the use of compact storage equipment would most likely increase the combined cost of building construction and shelving. In such cases it would be better to construct a building extension and equip it with conventional stacks than to install compact storage equipment in the old building. (3) Obviously, where base footings and/or floors are not strong enough to support compact storage equipment filled with books, the use of such equipment would be out of the question. For freestanding stacks, floors should probably be strong enough to support an average live weight of about $6_{5}$ pounds per square foot for compact storage. Floors of reading rooms in typical library buildings do not generally have such strength characteristics, and the installation of compact storage stacks would, therefore, constitute a hazard. (4) Whenever little-used books can be segregated and separately shelved on conventional adjustable shelves in an inexpensive warehouse or cooperative library storage center, it will probably prove to be the least expensive type of storage; and compact storage equipment should not be selected for such situations.

\section{Summary and Conclusions}

The question of where to use compact storage stacks and where not to use it is likely to continue to be a controversial question. Taking all factors into consideration, compact storage equipment can achieve some overall economy. Whether the savings outweigh certain alleged disadvantages of compact storage equipment cannot be categorically answered but will depend 
upon individual judgment in specific situations. There are situations in which the use of compact storage equipment seems advisable; there are other situations where the use of such equipment cannot be recommended.

Libraries with closed stacks may find that converting the stacks to compact storage may cost appreciably less than constructing a stack extension and equipping it with conventional shelf sections. Librarians should, however, not be misled into thinking that by more than doubling the storage capacity they can cut the overall cost of book storage in half.

Claims and counterclaims that have been made by the manufacturers may be briefly summarized to guide (or confuse) prospective purchasers of compact storage installations: (I) Remington Rand representatives claim that, as originators of the vertical file, they can manufacture drawer-type stacks at any time they see fit; but they feel that lack of proper maintenance and insufficient evenness of floors will cause malfunctioning of such equipment in libraries over the years and that replacement parts may not be available in years to come when a manufacturer may have discontinued his product. They feel that their scheme yields the greatest overall savings. (2) Ames representatives stress the troublefree easy operation of their drawers, the heavy-gage steel construction that permits users to stand on drawers without causing a permanent set in the steel, and their drawer-labelling system. They feel that quality of construction and ease of operation are more important than achieving the maximum increase in storage capacity. (3) Hamilton representatives feel their product is the most flexible, the most adaptable, and the most easily adjustable of all compact storage types. In their opinion, other types fail to achieve a sufficient increase in storage capacity to justify the designation of compact stacks. They feel that the disadvantages allegedly associated with the use of compact storage stacks either do not apply to their product or are not serious. They believe that their design "will in the long run prove a most satisfactory usable stack for practically every type of stack usage," both in closed and open stacks. They feel that the advantages of their product as compared to conventional shelving are so great that cost consideration should not receive primary attention. They also point out that stack aisles of less than 3 feet in width violate fire and safety laws in, at least, one state. (4) Art Metal representatives have not been so articulate as the other companies in making claims for their product; they may feel that their swing units speak for themselves especially as far as ease of mechanical maintenance and operation are concerned.

After a librarian has decided to use compact storage equipment, he will have to choose among the available products. In making his choice he will be guided in his evaluation by such factors as the following: ( I) Cost of shelving per lineal foot; (2) mechanical functioning of the equipment; (3), relative accessibility and visibility of the books; (4) efficiency in shelving, collecting, and shifting of books; (5) ease of shelf labeling; (6) adaptability of the equipment to the floor area dimensions under consideration; (7) adjustability of shelves or drawers; (8) hazards and safety features; (9) relative quietness or noiseness in operation; ( IO) appearance; (I I) adaptability to non-book users; (I 2) reconvertibility to non-compact storage. In other words, what is needed is an objective and impartial consumer research study of compact storage equipment. It is hoped that such a study will soon be published. ${ }^{6}$

- A detailed comparative study of the Ames, Art Metal, and Hamilton unit by Miss Grace E. Kite, Chief of the Circulation Division at Southern Illinois University LiCirculation Division at Southern Illinois Unive
braries, is under way and will be published soon. 
๘ু

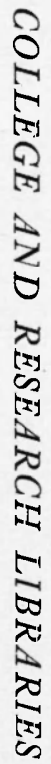

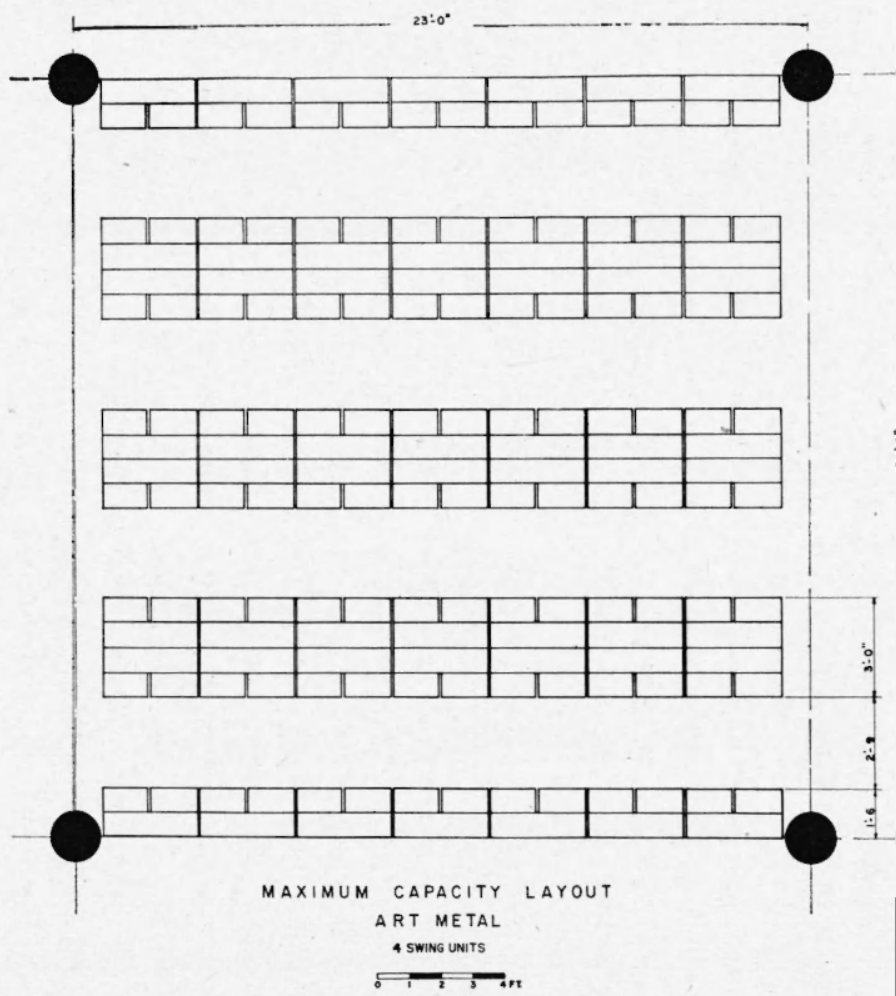

Figure I 


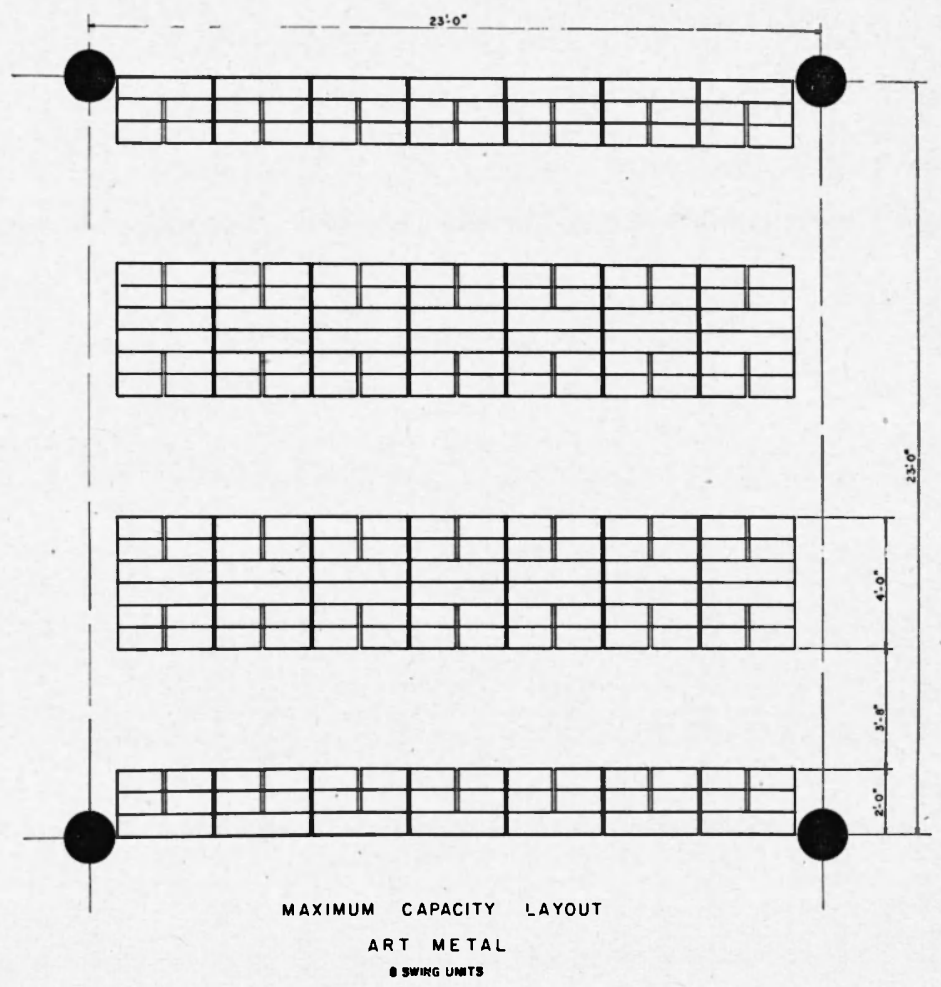

Figure 2 


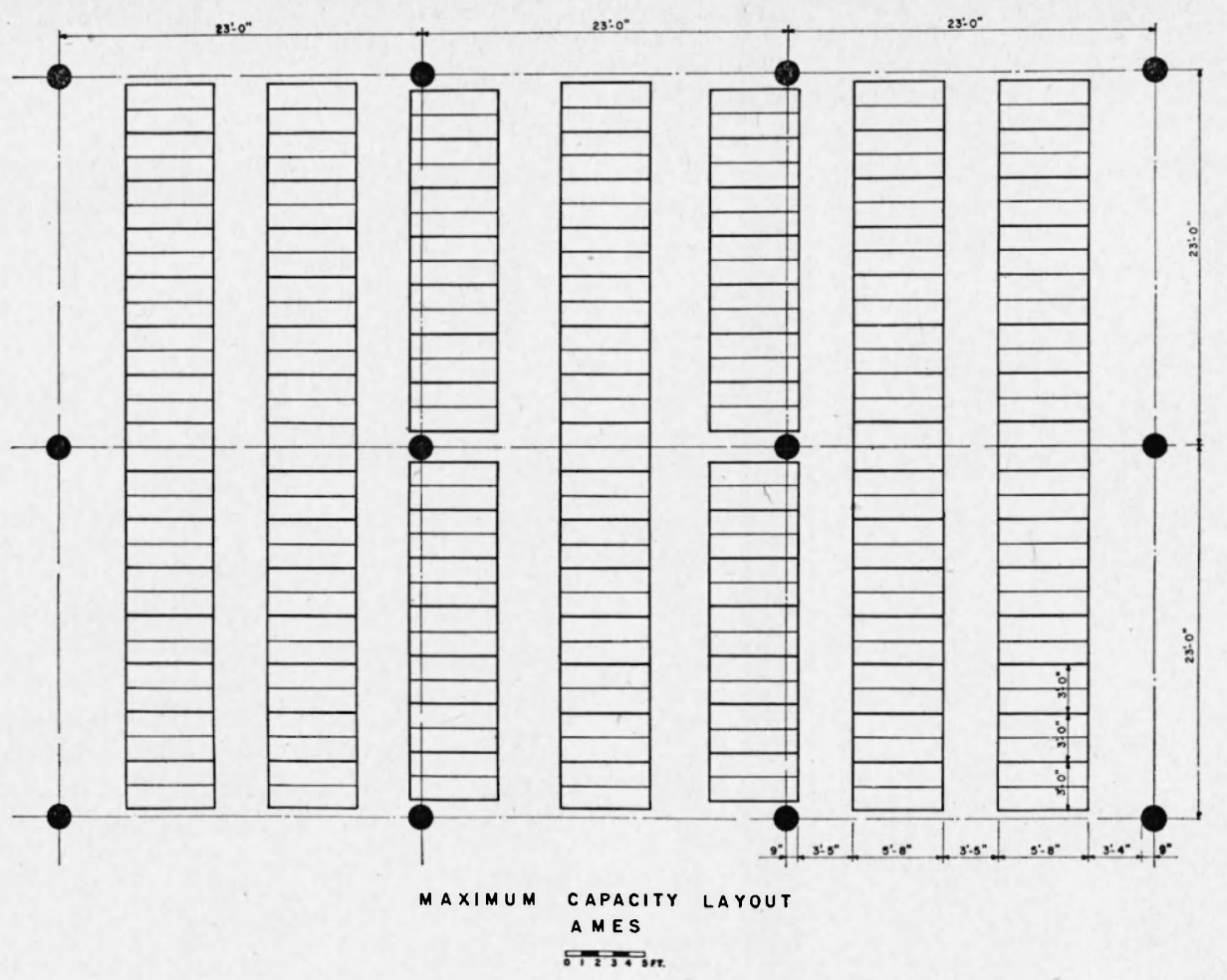

Figure 3

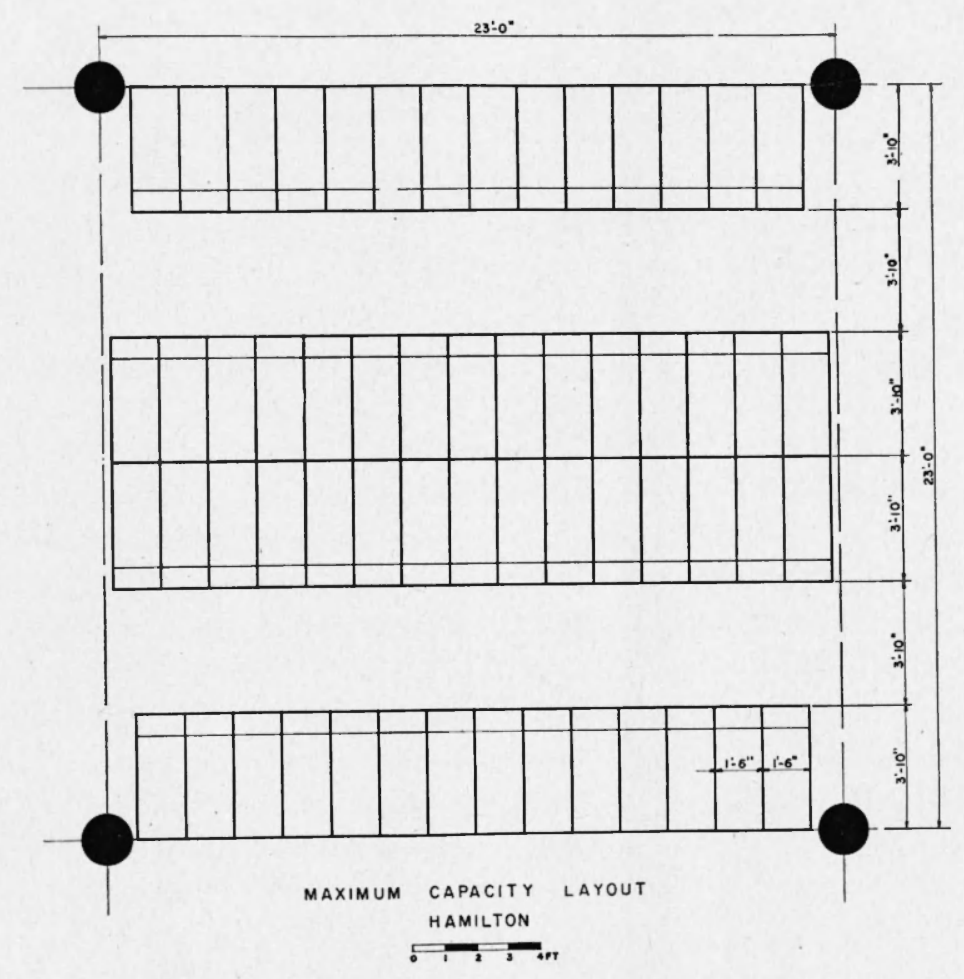

Figure 4 


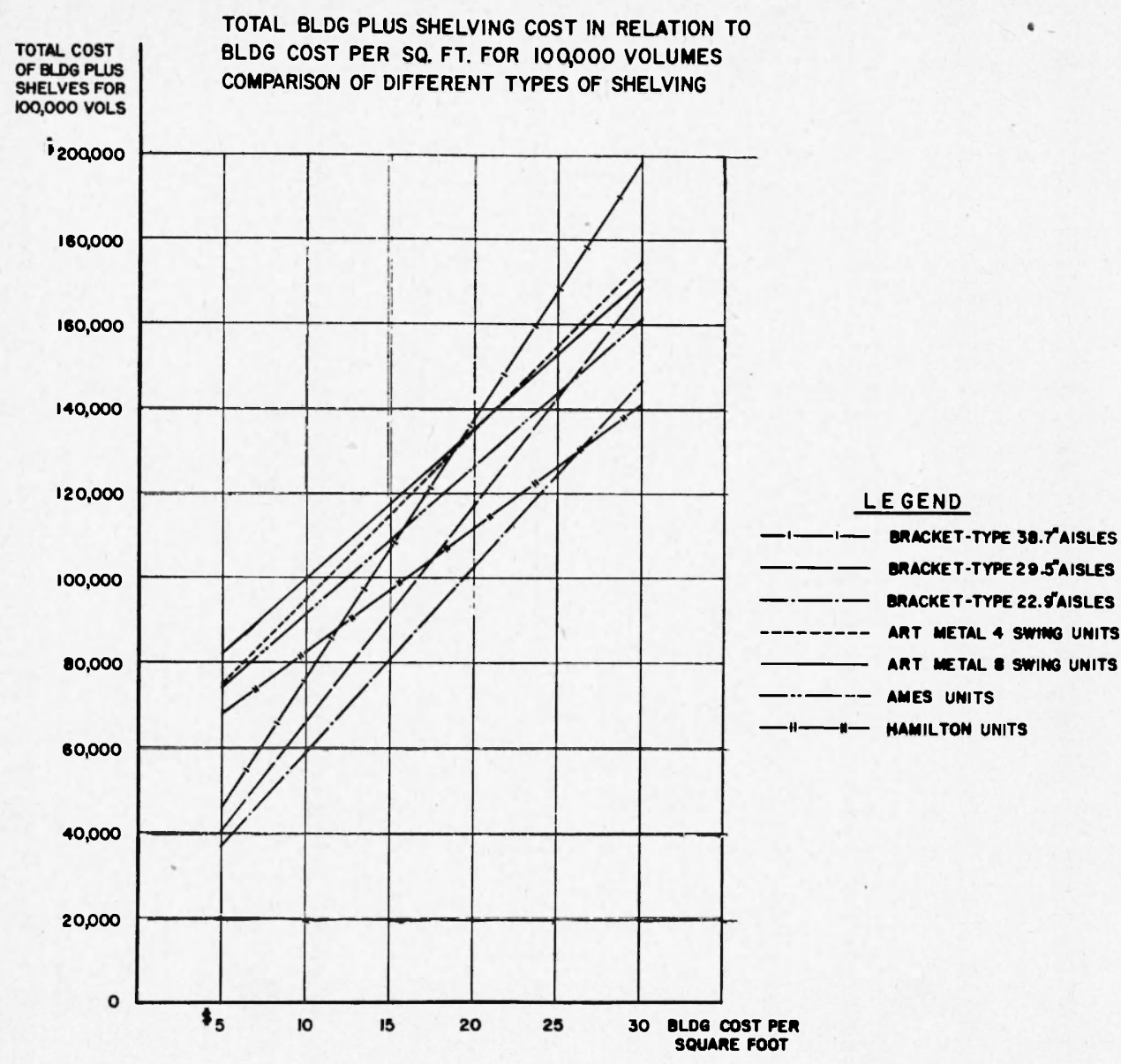

Figure 5

\section{On the Survey of a Research Library by Scholars}

\section{(Continued from page 29I)}

ing features seem worthy of note. It was a survey made "not by the distributors of books but by the users of books. ... It represents an appraisal of the library collections of the University by the experts in the several fields of knowledge represented on the University faculties." Though it was mainly confined to the libraries of the University of Pennsylvania, it occasionally reaches out and calls attention to other important collections in the Philadelphia area. It is designed to be definite and factual and to reveal weaknesses as well as strength. Though it cannot be claimed that the sin of self-glorification has been wholly avoided, it perhaps comes as near to objectivity as could be hoped for in any self-survey. 